\title{
The relationship between applying communication and technology tools with organization learning of school trainers
}

\author{
Jamal Hatamian, Abolhasan MaHroueI ${ }^{*}$, Sholeh HoseinineJAD, \\ Amin MAHROUEI
}

\begin{abstract}
Today's big organizations are not able to adjust with globalization without appropriate tools and technologies like organizational learning. The organizations have to change construction or equip to new tools to be able to cope with global changes. One of the most important tools to forward to this aim is development of learning organization. This study aimed to examine the relationship of using information and communication technology tools in empowering of the organizational learning and education. This cross sectional study was included all trainers of technical \& professional and work \& knowledge schools. In this study 225 cases selected out of 546 students through classification sampling method. The standard tools of Information Communication Technology and organizational learning questionnaires used to assess the samples. The reliability of questionnaire was between $0 / 79$ to $0 / 84$. Data analyzed by mean, standard deviation, Pierson and regression. The results revealed that there is significant relationship between using information and communication technology with organizational learning of trainers. Also, the level of using information and communication technology was predicted the organizational learning.
\end{abstract}

Keywords: communication and technology tools, organization learning, trainers.

\section{Introduction}

The technology changes, increased the communications and organizations are required to response to changed demands of customers. Investigating developments of organizations in last decades, we realized this organizations are not able to compete with others because of they could not adjust with social evolutions. The huge organizations with traditional structure are not able to adjust their structure with environmental developments and complications. They have to change their structure to survive or equip their self with new tools to compete with global evolutions (Khalili Araqi, 1382).In the new industrial world, no one escapes to globalization present at the global level and that has led organizations to generate world-class standards to create and maintain a competitive advantage that gives the possibility to engage in 
international trade machinery (Dimovski \& Škerlavaj, 2004). The complex situation of organizations requires modern organizations to rapidly adapt to environments changes. In this context, a thorough understanding of the process of organizational learning is vital. Organizational learning has emerged as one of the most promising concepts in strategic management after 1980 (Cardona, 2011).

The concept of organizational learning which was dramatically considered since 1990 is the result of two main factors: (a) the rapidly changes in the nature of the world, (b) the competitive environment of organizations. In fact the ways of learning and generating of knowledge is a key point of organizations empowerment. Learning requires to apply the knowledge in behavior of learners in their organization (Amini et al., 2014).

The organizations discovered that organizational learning and empowerment programs is main point in order to overcome to internal and external obstacles and create the context for fostering employees' empowerment by implementation of these programs (Zare, 2005).

Development of an organizations is depended to factors; employees strive to improve their capabilities and providing suitable conditions for this educational process by managers. Organizational learning is a dynamic process that enables organizations to quickly adapt to changes.

This process involves the production of new knowledge, skills and behaviors and includes specific organizational behavior which is applied in a learner organization. In such organizations, all of the learning conditions are provided for the members and individuals attempt continuously to apply what they have learned (Zhang et al, 2009). Proset and Boshel (1997) defined the organization learning, ability of organization as a whole to detect errors and correct them as well as changing knowledge and values of the organization so that the new problem-solving skills and to work to create new capacity.

Marquardt (1996), divided a variety of organizational learning into four categories, the first type of adaptive learning and happen when a person or organization to learn from experience and opening, this procedure can be one side or to side. One side learning is focused for stabilizing and maintaining information on system and emphasis on detection and error correction respectively. Tow side deepening learning system and includes the question of why errors occur or how succeeds occurred respectively. (Nekooyi-moghadam\&Beheshti, Bita).

Second learning type is predictive and it appears when organization learns from expected future. In third type of learning he called this type of learning as "learning in relation to learning" following Argyris \& Schon. In his idea when an organization involves with second type of learning the members discovers about content of previous organization. The people find out what they have done which facilitate learning or banded the learning of new strategies. The forth, learning is operational 
and Reginald Revans introduce this as working on real problems and applying solutions.

In Marquardt categorizations adaptive learning either one or two sided was indolent and mostly used to overcome on problem. While predictive and secondary is more Generative and Creative (same reference).

In addition the learning occurs in three levels of learning in individual learning, team learning and organizational learning. In individual, the person forming team and organization units. Peter M. Senge (1992) the main theories of organizational learning emphasized that organizations are learning via individuals, although learning of individuals are not warranted organizational learning but without individual learning organizational learning will not appear (Behnami,1387).

In new complicated organizations the teams are more substantial. Team learning implies that ream is able to think as a single entity, create and learn. In perspective of Peter Senge collective learning process comprise to capacity developed members and is aligned in such a way that the results will be what everyone really targeted.

Despite all the enablers and supporters of culture and learning may be individual and team organization as a whole is not learned. The organizational learning occurs through sharing knowledge ability to gain insight from experience, the essence of learning, experience and mental models to be members of the organization. Organizational learning is based on knowledge and experience that exists in the memory of the organization and it is depended to mechanisms such as policies, strategies, models based on stored knowledge. Argyris (1999) believed that organizational learning depends on sharing knowledge, beliefs and assumptions of the team knows (same reference).

Learning has three stages: Recognition (learning new concepts), behavior (developing new skills and abilities) and function (doing work, actually).In addition learning accrues in three levels of individual, group and organizational. I seems the term of organizational learning referring to individual learning in the organization, indeed organizational learning refers to the group or level of organizational learning. According to Bennet \& Bennet individual learning is possible through research, interviews, knowledge, experience, training, and development of effective mental models in mind, but organizational learning occurs when the group learns to interact, share knowledge and cooperatively act, therefore the combined capacity of group increases and gain the ability to understand and do effective actions (Bennet \& Bennet, 2008). Senge believed that organization learning happens through individuals although it does not implies that individual learning always results to organizational learning. Group learning is a process by which the capacity of members has been developed and aligned in a manner in that the results were desired (Senge, 1990). According to Senge five skills are required for organizational learning: personal mastery, shared vision, team learning, systems thinking (Marquard, 2002). 
In last decade of 1950 third view of information, technology and communication effected all education and learning systems in the world. Information technology and communication impacts the motivation and improves the meaning full context for learning (Afkhami, 2005). There is some evidence that ICT can give greater opportunities for accessing learning to those who need it the most. The eUser survey reveals, as mentioned above, that eLearning can extend the reach of training offers. Almost every second person taking an eLearning course states they would not have done training if it had not been available online (eUser 2005: 73).

Real et al (2006) tested the relationship of organizational learning with information technology communication via an empirical analysis carried out with a sample of 140 industrial companies. Their findings confirmed that information technology acts as an enabler of the organizational learning process and influences on the development of technological distinctive competencies, which allow the achievement of a better performance. These days the organizations which are not equipped by technology are in visible troubles (Marquard, 2002). In study conducted with Davies (2005) also in result of the use of computer simulations of electronic systems, the students rapidly developed far more independent working procedures than those anticipated by the teachers. The pupils' dependence on the teachers reduced progressively. Another positive outcome was that that it transformed the teachers' self-perception from a technical-vocational perception to an emphasis on the development of pupils' thinking skills and self-esteem (Davies 2005). Tippins and Sohi (2003) also revealed that there is significant relationship between organizational learning and organizational performance.

The efficacy of teachers in schools is substantial for education and organizational learning of any country. Teachers are one of the main components in learning and education efficiency. As Neefe (2002) study also indicated that the traditional methods of teaching is not appropriate in new days this study aimed to investigate the relationship of applying information technology and communication with organizational learning of students. 


\section{Review of literature}

In addition to traditional forms of information technology, such as phone, video post, met face to face, and notes; Media- computer communication systems such as email, bulletins, computer conferencing systems, electronic meeting systems, delivery systems and document flow management systems can facilitate the distribution of information. Studies have shown that such systems increase the participation and improves decision making processes (Hiltz, 1993). These systems, called groupware system, and collaboration resulted in the creation and distribution of experiences and insights.

These systems also supports the review and feedback mechanisms among the members. Thus, they not only improve communication but that they also support collaboration. Such active development of information systems, results to better interpretation and understanding the information.

Today multimedia systems, has emerged as a new class of complex informationmanagement systems to communicate with each other and they spread information through various media ( Gershman, 1993).

Technologies such as the world wide web (based on the concept of media) enables members with multimedia documents for any time, places and at any distance to international organizations communicate. The presence of this type of technology and other technologies, teaches more and promotes the understanding of internal, external affairs, organizational learning and learning organization creates permits (Nekooyimoghadam and Beheshti, Bita). The results of studies in the field of technology and organizational learning itself is confirmed the same.

Charles Harvey and John Danton (2002) conducted a study aimed to promoting organizational learning ground for several large companies engaged in research. The results showed that the requisite changes in the business environment, knowledge element in the development of organizational learning is a critical advantages, respectively. The competitive culture, encourage new ideas, risk-taking and involvement in decision-making are the main factors underlying learning (Sharifi and Islamia, 2007).

Blandford (2005) investigated the ability of the individuals concluded that how the self-efficiency leads to personal changes and growth potential of individual results to the organizational change and helps to increase the company and improve the effectiveness of organizations (Asghari and Tavakkolian, 1390).

Crossan (2003) investigation about organizational learning and renewal strategies found that organizational learning improves that efficacy of organization and costumer 
is able to evaluate this improvement. He also emphases on implementing organizational learning program for competitive advantages for organization (Dastgherdi et al, 1389).

Neefe(2001) ln study titled" comparing organizational learning items traditional and modern universities" (modern university considered as a university which implemented the scientific quality improvement and the traditional dose not implemented this program) the results showed that the components of organizational learning is different between traditional and modern universities and the learning level was higher in compare to traditional universities.

Tippins M.J. and Sohi R.S. (2003) regarding level of information technology and the performance of the organization, concluded that there is a significant relationship between organizational learning and organizational performance framework.

The results of study done by Dimovski \& skerlavaj (2003) entitled "Organizational Learning and ICT: a promising link" on the 220 top managers of commercial companies showed a significant positive correlation between organizational learning and information and communication technology.

Abdolmaleki (2001), in a study entitled "The relationship between organizational learning, change and innovation in education in 19 offices in Tehran," indicated that there was a high correlation coefficient between organizational learning and innovation and changes in the organization.

The results Sharifi \&Islamiyeh (2007), in a study entitled "The Relationship between organizational learning and the use of ICT in Azad University of Gharmsar," the 100 faculty members suggests that there was a significant relationship between organizational learning and using of ICT

Behnami (2007) believed that information technology is one of the most effective empowerment tools in learner organizations. So it could argued without information technology even in existence of other empowering tools the organization cannot improve properly. Learning organizations require at least the following features:

- intelligence and enterprise storage for preservation and dissemination of knowledge and experience;

- the possibility of cooperation, coordination and teamwork across geographical boundaries and even time;

- Communication to exchange messages, files, etc;

- Create, retrieve, and present timely information.

According to research review and its empirical foundations of education as a learning and teaching organization and the need to investigate the relationship between using 
information technology communication tools and organizational learning among students of technical institutes and professional work

The hypotheses of this study are as follows:

- There is relationship between using information technology communication with personal masters of students of technical institutes and professional work

- There is relationship between using information technology communication with mental models of students of technical institutes and professional work

- There is relationship between using information technology communication with shared visions of students of technical institutes and professional work

- There is relationship between using information technology communication with team learnings of students of technical institutes and professional work.

- There is relationship between using information technology communication with systematic thinking of students of technical institutes and professional work

- There is relationship between using information technology communication with organizational learning of students of technical institutes and professional work

\section{Methods}

This study was a cross sectional descriptive study.

Sampling

The study population was included all trainers of technical \&professional and work\& knowledge schools during 2013-2014. The total number of trainer students was 546(291 female and 255 male). 255 cases selected through cluster sampling methods and sample size calculate via Morgan table. The regions of city considered as cluster and students selected of 16 schools in region one and 23 schools of region two.

Tools

The study tools was researcher made and comprised 10 items which assessed methods and level of information technology and communication using among teachers. This questionnaire measures samples via likert options. Another researcher made was assessed organizational learning of students with 25 items according five dimensions of organizational learning which have been described by Senge. The reliability of questionnaire approved by professionals and chronbakh alpha revealed appropriate validity of 0.79 and 0.84 respectively.

Statistics

The SPSS version 18 used to analysis of data. Mean and standard deviation used to describe distribution of variables and characters of sample. Regarding investigating 
coefficient of variables Pierson used and Regression applied to predict the contribution of each variable.

\section{Results}

Descriptive findings was describe according five skills described by Senge comprised: personal mastery, shared vision, team learning, systems thinking.

Table 1: The characters of samples

\begin{tabular}{|c|c|c|c|}
\hline \multicolumn{4}{|l|}{ Variable } \\
\hline \multirow[t]{7}{*}{ subjects } & Electronic and computer & 53 & $23 / 55$ \\
\hline & $\begin{array}{l}\text { Child and family } \\
\text { management }\end{array}$ & 26 & $11 / 6$ \\
\hline & $\begin{array}{l}\text { Accountant and financial } \\
\text { affairs }\end{array}$ & 35 & $15 / 5$ \\
\hline & Imaginational arts & 28 & $12 / 45$ \\
\hline & Architect and building & 43 & $19 / 12$ \\
\hline & Mechanic & 21 & 9/34 \\
\hline & Chemical industry & 19 & $8 / 45$ \\
\hline \multirow[t]{6}{*}{ Job experiences } & $1-5$ years & 17 & $7 / 56$ \\
\hline & $5-10$ years & 67 & $29 / 78$ \\
\hline & $10-15$ years & 53 & $23 / 56$ \\
\hline & $15-20$ years & 37 & $16 / 45$ \\
\hline & $20-25$ years & 31 & $13 / 76$ \\
\hline & $25-30$ years & 20 & $8 / 89$ \\
\hline \multirow[t]{5}{*}{ Using ICT tools } & $0-5$ hours & 43 & $19 / 11$ \\
\hline & 5-10 hours & 78 & $34 / 67$ \\
\hline & 10-15 hours & 51 & $22 / 67$ \\
\hline & 15-20 hours & 33 & $14 / 66$ \\
\hline & 20-25 hours & 20 & $8 / 89$ \\
\hline \multirow{7}{*}{$\begin{array}{l}\text { The methods of communication between students } \\
\text { and teachers }\end{array}$} & Only email & 21 & $9 / 3$ \\
\hline & Mobile & 114 & $50 / 7$ \\
\hline & Website or web log & 10 & $4 / 4$ \\
\hline & Email and mobile & 28 & $12 / 4$ \\
\hline & Email and websites & 6 & $2 / 7$ \\
\hline & $\begin{array}{l}\text { Mobile \& website and } \\
\text { email }\end{array}$ & 13 & $5 / 8$ \\
\hline & anyone & 21 & $9 / 3$ \\
\hline
\end{tabular}

The results of descriptive analysis as it is obvious in table shows that $23 / 55,11 / 6$, $15 / 5,12 / 45,19 / 12,9 / 34$ and $8 / 34$ percentage of students were studding is subjects of 
electronic and computer, child and family management, accountant and financial affair, imaginational arts, architects and building, mechanic, chemical industry respectively.

The majority of teachers $(30 \%)$ had 5-10 years of experience which implies most of them are young. The highest rate of information technology usage was between 5-10 hours. Considering the subjects included electronic and computer this level of information technology usage seems less. Also the most common communication tool is mobile and more than half of students uses mobile.

\section{Hypotheses}

1- There is significant relationship between information technology and communication using level with personal mastery

Table 2: The correlation coefficient of information technology and communication with personal mastery

\begin{tabular}{|l|l|l|l|l|l|}
\hline variable & $\mathrm{R}$ & $\mathrm{cd}$ & $\mathrm{df}$ & $\mathrm{t}$ & $\mathrm{sig}$ \\
\hline $\begin{array}{l}\text { of information technology and communication } \\
\text { with personal mastery }\end{array}$ & 0.455 & 0.207 & 223 & 7.63 & 0.000 \\
\hline
\end{tabular}

The table shows that correlation coefficient is 0.455 with $7.63 \mathrm{t}$ in $223 \mathrm{df}$ is significant in 0.05 level. Therefore, there is significant relationship between information technology and communication using level with personal mastery. This table implies that increased using information technology and communication leads to higher personal mastery. In fact information technology and communication predict 20 percentage of personal mastery.

2- There is significant relationship between information technology and communication using level with mental models

Table 3: The correlation coefficient of information technology and communication with mental models

\begin{tabular}{|l|l|l|l|l|l|}
\hline variable & $\mathrm{R}$ & $\mathrm{cd}$ & $\mathrm{df}$ & $\mathrm{t}$ & $\mathrm{sig}$ \\
\hline $\begin{array}{l}\text { of information technology and communication } \\
\text { with mental models }\end{array}$ & 0.392 & 0.154 & 223 & 3.360 & 0.000 \\
\hline
\end{tabular}

The table shows that correlation coefficient is 0.392 with $3.360 \mathrm{t}$ in $223 \mathrm{df}$ is significant in 0.05 level. Therefore, there is significant relationship between information technology and communication using level with mental models. This table 
implies that increased using information technology and communication leads to higher mental models. In fact information technology and communication predict 15 percentage of variance of mental models.

3- There is significant relationship between information technology and communication using level with shared visions

Table 4: The correlation coefficient of information technology and communication with shared visions

\begin{tabular}{|l|l|l|l|l|l|}
\hline variable & $\mathrm{R}$ & $\mathrm{cd}$ & $\mathrm{df}$ & $\mathrm{t}$ & $\mathrm{sig}$ \\
\hline $\begin{array}{l}\text { of information technology and communication } \\
\text { with shared visions }\end{array}$ & 0.386 & 0.149 & 223 & 6.25 & 0.000 \\
\hline
\end{tabular}

The table shows that correlation coefficient is 0.386 with $6.25 \mathrm{t}$ in $223 \mathrm{df}$ is significant in 0.05 level. Therefore, there is significant relationship between information technology and communication using level with shared visions. This table implies that increased using information technology and communication leads to higher shared visions. In fact information technology and communication predict 15 percentage of variance of shared visions.

4- There is significant relationship between information technology and communication using level with team learning

Table 5: The correlation coefficient of information technology and communication with team learning

\begin{tabular}{|l|l|l|l|l|l|}
\hline variable & $\mathrm{R}$ & $\mathrm{cd}$ & $\mathrm{df}$ & $\mathrm{t}$ & $\mathrm{sig}$ \\
\hline $\begin{array}{l}\text { of information technology and communication } \\
\text { with team learning }\end{array}$ & 0.450 & 0.203 & 223 & 7.53 & 0.000 \\
\hline
\end{tabular}

The table shows that correlation coefficient is 0.450 with $7.53 \mathrm{t}$ in $223 \mathrm{df}$ is significant in 0.05 level. Therefore, there is significant relationship between information technology and communication using level with team learning. This table implies that increased using information technology and communication leads to higher team learning. In fact information technology and communication predict 20 percentage of variance of team learning

5- There is significant relationship between information technology and communication using level with systematic thinking 
Table 6: The correlation coefficient of information technology and communication with systematic thinking

\begin{tabular}{|l|l|l|l|l|l|}
\hline variable & $\mathrm{R}$ & $\mathrm{cd}$ & $\mathrm{df}$ & $\mathrm{t}$ & $\mathrm{sig}$ \\
\hline $\begin{array}{l}\text { of information technology and communication } \\
\text { with systematic thinking }\end{array}$ & 0.415 & 0.172 & 223 & 6.81 & 0.000 \\
\hline
\end{tabular}

The table shows that correlation coefficient is 0.415 with $6.81 \mathrm{t}$ in $223 \mathrm{df}$ is significant in 0.05 level. Therefore, there is significant relationship between information technology and communication using level with systematic thinking. This table implies that increased using information technology and communication leads to higher systematic thinking. In fact information technology and communication predict 17 percentage of variance of systematic thinking. Systematic thinking

6- There is significant relationship between information technology and communication using level with organizational learning

Table 7: The relationship of information technology and communication with

\begin{tabular}{|l|l|l|l|l|l|}
\hline \multicolumn{7}{|c|}{ organizational learning } \\
\hline variable & SS & df & MS & F & p \\
\hline Regression & 17435.1 & 1 & 17435.1 & 77.89 & 0.000 \\
Remained & 49917.39 & 223 & 223.85 & & \\
Total & 67352.52 & 224 & & & \\
\hline
\end{tabular}

\begin{tabular}{|ll|l|l|l|l|l|}
\hline & & $\mathrm{R}$ & $\mathrm{SD}$ & $\mathrm{B}$ & $\mathrm{t}$ & $\mathrm{P}$ \\
\hline $\begin{array}{l}\text { Using information technology and } \\
\text { communication }\end{array}$ & 1.068 & 0.121 & 0.509 & 8.83 & 0.000 \\
\hline
\end{tabular}

The results of regression with $\mathrm{F}$ (77.89) in $\mathrm{P}>0.05$ level indicated the relationship between using information technology and communication with organizational learning.

\section{Discussion and conclusion}

This study was aimed to investigate the relationship of using information technology and communication tools with organizational learning among 225 students. The results of study indicated significant relationship between information technology and communication using with organizational learning and subscales i.e. personal mastery, shared visions, team working, systematic thinking. The results indicated that information technology and communication using predicts 20 percentage of variance 
of personal mastery. This finding is in line with results of Sharifi and Slamiyeh (2007) which showed that personal skills is related with information technology and communication using in Gharmsar University-Iran. Blandford (2005) also believed that personal skills leads to personality improvement and these peoples are coprative in empowerment and enhancement of organizational efficacy.

There was significant relationship between information technology and communication using with mental models. Harvey \& Denton (2002) also noted that competitive culture, encouraged new idea and disclosing to risks in decision making are required items of empowered organizational learning. The third hypothesis confirmed that information technology and communication using boosted shared visions among students. Shine (2007) also highlighted the importance of motivation and shared visions in learning as peoples with same targets are eager to new experiences and subjects. Another result of present study showed that information technology and communication using leads to increased team work. This result is in harmony with Real et al (2006) study.

Also systematic thinking of students was in relation with information technology and communication using. The results of regression showed that information technology and communication using predicts organizational learning and there is a liner relationship between these two variables. So information technology and communication using predicts 26 percentage of organizational learning variances. This result is in harmony with results of Sharifi and Slamiyeh (2007) and Dimovski \& Skerlavaj (2004).

It is necessary to take a broad view in order to determine how information technology and communication impacts the learning. This is because of educational achievements are shaped not only by the education but also by the socio-economic background of the learners, their socio-cultural environments, the changing skills and competences that are necessary for employment, education and training, selfdevelopment and participation in society. This clarifies partly why non-formal learning, informal learning and adult learning are increasingly seen as crucial for the future of learning (Punie et al, 2006).

There is evidence that educational achievements are positively influenced by information technology and communication. Learning boosts the individual and organizational performance and without learning organization cannot adjust with changes. Finally these days education and learning are two main factors for individual and organizational extent. The efficacy and quality of education system is majorly depends on teachers and students. Considering huge change in information and technology the traditional methods is not suffusion for learning and education and without new skills people are not able to join globalization in competitive world. Therefore there is need to provide appropriate situation for teachers and students 
regarding using updated information technology and commutation tools. The authors suggests designing new programs and holding the educational classes, special attention to the creativity and innovation of teachers, respecting and encouraging them, delegation of authority and assignment of tasks, giving autonomy and freedom of action to employees, team formation and development of participatory management.

\section{Acknowledgment}

The authors are thankful from students, schools staff and teachers who they are cooperated nicely in conducting this study.

There is no competing of interest in this study

\section{References}

1. Abdolmaleki, Joseph. (2001). Examine the relationship between organizational learning and change and innovation in education departments of 19 regiouns of Tehran, Master dissertation, Allameh Tabatabai University,Tehran-Iran.

2. Amini, H., Rahmanian, M., Sadeghifar, K., Bay, M., Afravi, N., \& Sedaghat, M. (2014, July). The Relationship between Empowerment and Organizational Learning of Physical Education Teachers.

3. Asghari, MH. Tavakkoli, F. (1390). The relationship between the application components of the learning organization and quality of work life, Journal of Educational Psychology, Islamic Azad University, Issue I, the spring 90.

4. In Biological Forum (Vol. 6, No. 2, pp. 218-223). Satya Prakashan.

5. Behnami Joseph. (2007), organizational learning, strategy journal, No. 192.

6. Bennet, D., \& Bennet, A. (2008). Engaging tacit knowledge in support of organizational learning. Vine, 38(1), 72-94.

7. Blandford, Mark Roy. (2005). It's all about me: subtle change through personal mastery. UMI Proquest digital dissertation. ISBN.0-494-04104-8.

8. Cardona, D. (2011). ICT and its impact on organizational learning. Postmodern Openings, (07), 111-141.

9. Davies, Ch. (2005) "14-19 and Digital Technologies: A Review of Research and Projects", Futurelab Report Series No. 13, Bristol: Futurelab. http://www.futurelab.org.uk/

10. Dastgerdi, K. et al. (1389). Its enabling organizational learning Physical Education Organization of Islamic Republic of Iran, Sports Management, Issue 7, Winter 89.

11. Dimovski, V., \& Skerlavaj, M. (2004). A stakeholder theory approach to the organisational performance and influence of information-communication 
technology: Model conceptualisation and testing. Economic and Business Review for Central and South-Eastern Europe, 6(3), 245.

12. eUser (2005) "Synthesis and Prospective Analysis", D5.1: First Synthesised Inputs to Knowledge Repository, Including Initial Survey Results and Good Practice Examples, August 2005, eUser project. http://www.euser-eu.org

13. Ghahremani, Muhammad. (2003), Learning Organization: result of management centuries, knowledge management magazine, the first issue.

14. Harvey, Charles \& Denton, John. (2002). To Come of Age: The Antecedents of Organizational Learning. Journal Of Management Studies. Vol 36, Issue 7. pp $897-918$.

15. Khalili-araqi, Mary. (2002). Learning organizations: necessary for the development, management magazine, No. 137.

16. KhanliZadh, Roqhaeh. (2009). The relationship between empowerment and organizational learning, change management journal, Issue 3.

17. Marquard Michael. (2002). Building The Learning Organization Davies Black publishing.

18. Neefe, Diane Osterhaus (2001). Comparing Levels of Organizational Learning Maturity of Colleges and Universities Participating Traditional \& Nontraditional (Academic Quality Improvement Project). Accreditation Processes.

19. Nekooyi-moghadam, Mahmmod. Beheshtifar,Malikeh, Bita, learning organization, development and management of the Ministry of Health and Medical Education, First Edition.

20. Punie, Y., Zinnbauer, D., \& Cabrera, M. (2006). A review of the impact of ICT on learning. Working paper prepared for DG EAC. Seville: JRC-IPTS (Joint Research Centre-Institute for Prospective Technological Studies).

21. Real, J.C., Leal, A., Roldan, J.L. (2006). "Information technology as a determinante of organizational learning and technological distinctive competencies". Industrial marketing management, 35:505-521.

22. Schein, Edgar. (2007). Organizational learning, culture and career. Monthly contract managers, 20, 86.

23. Senge. Peter, (1990). The Fifth Discipline: The art and practice of learning organization. Doubleday Dell; New York.

24. Sharifi, AA. Islamia, F. (2007). Examine the relationship between organizational learning and the use of information and communication technologies in the Islamic Azad University of Gharmsar, a new approach in the Journal of Educational Management, Islamic Azad University of Shiraz, 1(2), 2007.

25. Tippins, M.J. and Sohi R.S. (2003). "It competency and firm performance: is organizational learning a missing link"? Strategic management journal, 24(8), p: 745-761. 
Bulletin de la Société Royale des Sciences de Liège, Vol. 85, 2016, p. 778 - 792

26. Zare, G. (2005), the relationship between psychological empowerment and organizational factor in the Physical Education Thesis, Master of Science, Faculty of Physical Education and Sport Sciences, Tehran University.

27. Zhang. Li, Tian. Yezhuang, Zhongying Qi, A, (2009). A conceptual model of organizational learning based on knowledge sharing, School of Management, Harbin Institute of Technology, China. 